\title{
A Implantação do Projeto Terapêutico Singular (PTS) no Cenário Oncológico
}

Schmidt, Denise Pasqual; Neckel, Vanessa Carla; Lima, Caie Pires de Deus; Simas, Tassieli Mendes; Oliveira, Natália de; Groth, Elisandra Pereira

UFSM/HUSM - dps@ufsm.br

INTRODUÇÃO: a Política Nacional de Humanização corporifica um acervo de estratégias para obtenção da qualidade da atenção e gestão em saúde no SUS, configurando construção de um espaço de trocas de saberes e grupalidade em ambiência da saúde. É, portanto, neste cenário que emergem as discussões acerca do Projeto Terapêutico Singular (PTS). o PTS configura-se como uma discussão de casos clínicos, proporciona uma atuação integrada da equipe e considera outros aspectos além do tratamento médico. Assim, o usuário é visto na sua totalidade, na dimensão bio-psico-social. Tal estratégia, filiada ao movimento dialético, sublinha a ação de desconstrução/reconstrução de saberes e modos de fazer, suscitando desafio profissional. OBJETIVOS: a pesquisa-ação tem como objetivo prático implantar o dispositivo de cuidado PTS num hospital que atende pacientes oncológicos adultos e crianças e como objetivo de conhecimento investigar as vivências de implantação do PTS neste locus, gestando um novo modelo assistencial em saúde. METODOLOGIA: o projeto optou pela pesquisa-ação, adotando seminários como técnica para a recolha de dados. como instrumentos de coleta de dados estão sendo adotados o questionário e o diário de campo. É importante ressaltar que a implementação do PTS pressupõe a escolha de um caso clínico, já a seleção dos sujeitos da pesquisa acontecerá a partir dos seguintes critérios de inclusão: a) ser profissional que preste assistência ao caso clínico atendido; b) tenha consentido em participar da pesquisa-ação. em observância aos princípios éticos e em sintonia com a Resolução 196/96, a presente pesquisa adotará o Termo de Confidencialidade e o Termo de Consentimento Livre e Esclarecido. RESULTADOS/DISCUSSÃO:A pesquisa está em fase de execução, porém alguns achados já se tornam presentes. no cumprimento das etapas necessárias ao estabelecimento do PTS, a equipe multiprofissional está seguindo cinco momentos: a) Diagnostico, b) Definição de metas, c) Divisão de responsabilidades, d) Negociação, e) Reavaliação. para tal performance, a equipe multiprofissional discute caso a caso, possibilitando a elaboração de projeto estratégico, com propostas de intervenção, ações e tomadas de decisão, quanto a melhor maneira de viabilizar as necessidades do paciente/família. CONCLUSÃO: a implantação de tal dispositivo demandou a ação integrada de gestão para garantir o atendimento individualizado, humanizado e ético ao usuário e família, promovendo assim, a melhoria da qualidade de vida e do atendimento prestado. Assim Identificou-se também uma forma diferente de interação entre os envolvidos no cuidado do paciente

Schmidt, Denise Pasqual; Neckel, Vanessa Carla; Lima, Caie Pires de Deus; Simas, Tassieli Mendes; Oliveira, Natália de; Groth, Elisandra Pereira. A Implantação do Projeto Terapêutico Singular (Pts) no Cenário Oncológico. In: Anais do Congresso Internacional de Humanidades \& Humanização em Saúde [= Blucher Medical Proceedings, num.2, vol.1]. São Paulo: Editora Blucher, 2014. ISSN 2357-7282 DOI 10.5151/medpro-cihhs-10486 